\title{
Psychic envelopes among adolescents: a test of modelling with a projective test in relation to school refusal
}

\begin{abstract}
In this article, we develop a psychodynamic reflection on the place and functions of psychic envelopes in adolescents using a specific tool, the FAST (Family System Test). The concept of ego-skin developed by Anzieu ${ }^{1-4}$ is the origin of a particular functional approach of psychic functioning, which relates to the concepts of group dynamics largely developed by the same author. ${ }^{5}$ This approach makes it possible to locate "operationally" the dysfunctions of the relation between the subject and its environment, such as their incidences on the individual, family and social economy. With the adolescent subject, these dynamics appear able to bring a clinical intelligibility to us, in particular in terms of childrens' relationships at school. To this end, the use of a singular projective test such as the F.A.S.T. (Family System Test) brings an innovative perspective with the prospect for psychodynamic application in the field of school refusal and schooling in general. The use of the FAST and the application that we propose allows to jointly carrying out evaluation and brief psychotherapy.
\end{abstract}

Keywords: psychic envelopes, adolescence, operationalization, family system test, school refusal

\author{
Volume 8 Issue I - 2017 \\ Gilles Brandibas,' lan Tucker,' Jean Luc \\ Sudres,' Amal Bernoussi,' Francois \\ Njiengwe' \\ 'Clinical Psychologist, Institute Clinical Pratices and Applied \\ Research, France \\ ${ }^{2}$ School of Psychology, University of East London, UK \\ ${ }^{3}$ Clinical Psychologist, University of Toulouse Jean Jaur?s, France \\ ${ }^{4}$ Department of Psychology, University of Picardie Jules Verne, \\ France \\ ${ }^{5}$ Department of Psychology (FLSH / PH-PS), University of \\ Douala, Cameroon
}

Correspondence: Gilles Brandibas, Clinical Psychologist, PhD in Psychopathology, IPCRA (Institute Clinical Pratices and Applied Research), Fontenilles, France,

Email gillesbrandibas@aol.com

Received: November 20, 2016 | Published: July 19, 2017

\section{Discussion}

In our society, adolescents are wrapped up by families in a more or less appropriate way and do not succeed in a process of individuationsocialization. This situation regularly disrupts both their academic development and their quality of personal and family life. Thus we developed a psychodynamic reflection on the place and functions of psychic envelopes in the adolescent using a specific tool, the FAST (Family System Test).

\section{From ego-skin to psychic envelopes}

In his first article in 1974, Anzieu ${ }^{1}$ presented the ego-skin as a place of exchanges between the internal psychic sphere and the surface of the body. This place of exchange allows the development of lived experience, but contains it in order to protect from the too intense excitations of outside. In 1986, Anzieu ${ }^{4,6}$ added that the ego-skin makes it possible for the child "to bring in itself an ego containing the psychic contents". Ego-skin is developed into the concept of psychic envelope, which itself emerges from the related concepts of sound envelope, olfactive envelope, envelope of suffering, and strips of the dream $^{1}$. This is based on the notion of psychic apparatus containing and growing into different kinds of envelope, e.g. sound envelope, which all link inside (body) and outside (environment). All these interfaces contribute to associate the various functions of ego-skin in a somato-psychic singularity, previously under-explored up to this point (Doron, 2000). The psychic envelope is different from the ego-skin in that it is not a closed limit that supports the filtering of the stimuli of the external world. The envelope is located neither outside nor inside, it is the border (Mellier, 2014). Thus, it authorizes the exchange between the social environment of the subject and the psychic apparatus; with psychic development being closely related to the quality of this exchange. Based notably on Winnicott's handling and holding, ${ }^{7}$ three functions were initially highlighted: containing, limit between the inside and the outside (which is a protection compared to the external stimuli), and communication with the environment. These functions show that ego-skin, agreed here as a kind of psychic envelope, is an interface which at the same time allows the exchange with outside and protection with respect to outside. All things considered, this interface is a guarantor of the psychic integrity of the subject, as the skin is guarantor of its physical integrity. Moreover, it becomes a place where exchanges with others occur. It founds and makes live the relation, where the interaction with the family circle, in particular with the mother, finds its foundations. Thus the concept of ego-skin "respects the specificity of the psychic phenomena compared to organic realities as with the social facts". ${ }^{3}$ Teens and families weave a common skin with group and psychic confusions that require assessment.

\section{Adolescence and internal groupality and/or psychic envelope}

Classically, the groupality ${ }^{2}$ is understood as the intrapsychic organization of the representatives of the social environment of a subject. As for the psychic group envelope, it appears as the interface allowing the transition between group and psychic apparatus. The groupality would be structural and the psychic group envelope would be functional. The concepts of groupality and internal group make it possible "to understand the processes starting from the psychic world and not only like one sociological or psycho-sociological problematic". ${ }^{8}$ The problem is thus to distinguish internal groupality and psychic group envelope. Both have on the one hand an own structure and functions on the level of the narcissistic shoring, and on the other hand a finality of interface between the subject and his/her environment. In other words:

a. The psychic group envelope refers to the group itself which surrounds the subject;

b. The internal groupality is the internal organization of the objects and the interface between outside and inside. 
Interface or envelope are thus terms used to construct a notion that makes it possible to apprehend psychic space with intra and interindividual, between the "inside" and the "outside". The psychic group envelope does not mean the real members of the group but what they can represent, such as their incidence on the level of the relation and the individual psychic apparatus and/or groupality. We will use the terms here of:

a. Internal groupality to mean intrapsychic representatives of the social environment of a subject;

b. Psychic group envelope to mean their organization as a psychic envelope intended to be used as interface between the subject and his social environment.

Let us recall that for Kaës $\mathrm{R}$ it is:

"Intrapsychic formations equipped with a structure and functions of connection between the drives, the objects, the representations and the components of the psychic apparatus, as far as and under the aspect where they form a system of relations which bind their elements to the others. According to this design, the psychic groupality is a specific organization of the psychic matter. It is a not simple anthropomorphic projection of the intersubjective groups, nor the pure introjection of the objects and the intersubjective relations. It has a consistency like formation of unconscious". ${ }^{11}$ Thus, the interface results in integrating the properties and the functions of the social environment into its own structure. It is organized around the representatives of the environment: the family, the school, peers, and the community. In fact, the parents weave their representatives on the level of the internal groupality. These representatives will be able to feed by the effect of the interface and its functions the various components of the psychic apparatus, in particular the parental imagos, the Super-ego and the ideal of Ego. The parental imagos will influence, according to the organization of the internal groupality, the secondarily supplied representatives who assume with the subject or others a parental function. The Superego is fed by representatives who assume a function of authority and the Ego ideal by representatives who achieve an ideological function, mythical, axiologic or of memory. When the functions of the interface dysfunction are not able to adapt to the conflicts caused by the interaction between environment and psychic apparatus, the development which allows the distance with the internal objects becomes difficult. They appear dangerous and are replaced by real objects (less threatening) such as the peers, or by objects idealized or against-identifying (gods, stars of rock'n'roll, satanic rites, etc). Adolescence is a period during which the psychic group envelope will necessarily have to adapt because it is altered by the arrival of puberty, and by the resurgence of the separation-individuation process. Can the recourse to cross-generational identifying area be regarded as a "normal" adaptation tending to preserve the infantile investments?

What we observe in the relationships of the teenager with his/her social environments is the adaptation of the envelope in comparison with the modifications of the internal groupality. Quality of narcissistic bases will influence the capacity on adaptation of the internal groupality, and consequently the capacity to develop distance with the objects. Chapelier ${ }^{8}$ note the need that has the adolescent "to be based on an identifying area used in a transverse and either crossgenerational way".

\section{The contingent body}

In considering concepts of psychic envelope and ego skin, we are drawing on areas of social theory that place emphasis on theorising the 'body' as the product of both internal (individual) and external (social) forces and practices. Understanding how adolescent bodies are affected by their social and geographical environments requires thinking the body as not a static entity waiting to be understood by existing knowledge frameworks, but actually as always-already a malleable entity that is in-part produced according to the contextual practices that it exists within. More specifically, the adolescent body can be conceptualised as being produced through an interrelation of inner drives and social practices, e.g. school, family and friend relations. In considering how bodies are socially constituted, one can consider Annmarie Mol's ${ }^{12}$ ethnography of the body in studying the disease atherosclerosis in The Body Multiple. Here we see how bodies exist in multiple ways, contingent on the practices within which they are produced. Mol details the different ways that bodies are practiced in a hospital setting in respect of the disease artherosclerosis. This is a different approach than seen in the volumes reviewed, as it places prime focus on enactment. This is Mol's term, which relates to approaching the body through the ways that medicine interacts with, relates to, puts into place, and forms the body in its various and variable practices. ${ }^{12} \mathrm{Mol}$ does not set out to understand how the body is known by medicine, but rather how it is done. This involves an approach that crosses disciplinary boundaries. It is not distinct bodies that are conceptualised, but rather different bodies in each particular practice at work. This contextualises bodies in terms of the social environments (or territories) in which they operate. For example, the body made visible in the laboratory is dependent upon the microscopes, scalpels and medical knowledge at work in that setting. The multiple nature of the practice of bodies involves the connecting of many different factors (e.g. doctors, patients, legs, thickened intima, microscopes, slide lenses), within the variety of settings (e.g. pathology laboratory, consultation room) in which artherosclerosis is enacted. These factors are all productive of knowledge regarding the body in the disease artherosclerosis, and involve the interconnecting of processes that are not reductive to society or individual. Indeed, talk of bodies or society as distinct has no use in this context, as experience and knowledge of bodies are wholly bound up in practices that operate across boundaries. In this way, one can consider not $a$ body, but multiple bodies, ${ }^{13,14}$ as how embodiment is experienced and operates is always dependent on the setting within which it operates. Attempting to develop a generalised theory of the operation of all bodies may in some sense be a futile endeavour, if we take it that bodies operate in concert with the constituents of constantly reworking settings. Bodies are not independent of their surroundings. In doing this, we accept the productive nature of experience that Mol puts forward. To understand bodies, is to conceptualise them as constantly operating in dialogue with constituents of our environments, and in doing this recognise that what we are looking at are the ways that bodies are made visible, namely, the interactions that lead bodies to operate in their context-dependent ways. Social theories of embodiment are valuable for placing emphasis on how environments impact upon experience, and in relation to Anzieu's concepts of egoskin and psychic envelope, how the subject and environment meet at the border of the body, produced through individual drives and social practices. With the body acting as the interface of both, hence Anzieu's notion of ego-skin, with reference both to inner drives (i.e. ego) and somatic factors (i.e. skin).

\section{Adolescence, the family and the school: for setting out of envelopes to assessment}

\section{The school maladjustment}

What about the various types of maladjustment on the level of the provision of education for adolescents? From where can these difficulties come? Is it the conditions of the schooling, affective 
disorders, and family problems or more largely of environmental distances, or complex relationship between all these factors? In the case of school refusal, if the adolescent manages to reach the dynamics evoked on the level of his family, it is difficult for him/her to do it on the level of the school. ${ }^{15}$ School remains with adolescent in a hierarchy and an adult/child relation comparable with that of the child in latency period at the primary school. Faced with such a shift, any space of relation seems vowed with failure. ${ }^{16,17}$ Let us take as example the distinction between truancy and school phobia, understood as a differentiation between externalized and internalized symptoms, and skewing the recourse to a subjective responsibility: the truant "does not want" while the school phobic one "cannot". We can retort with this objection that in the case of the school phobia, one seeks the origin well, as for example the separation anxiety related to difficulties of separation mother-child. The chronology is taken into account, returning the disorder at an infantile origin. However, while leaving it with the presence of separation anxiety, we limit the field of investigation to salient symptomatic aspects.

\section{Modeling psychic apparatus and its bond with environment}

The psychic apparatus builds at the same time self-centred manner (dynamic psychic) in an out-centred way. These are the bonds that the child and the mother build together who will allow this one to weave it and to consolidate its narcissistic bases. Indeed, narcissism by definition is not confined with intra-psychic, but is also what connects an intra-individual dynamic and an interindividual dynamics. We suggest a modeling of the relations between the subject and the systems that constitute its immediate environment (Figure 1).

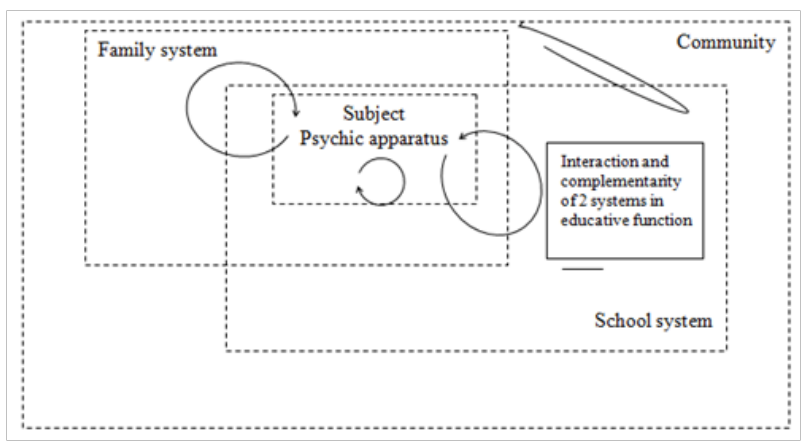

Figure I Interaction intra and cross-systemic of adolescent, family and school.

In this modeling, the subject appears clearly in interaction with the family and school systems. It has its own psychic apparatus which is built and has its own functioning. The construction of the subject is done in interaction with its social and family environment. The environment brings the individual to mature, determining the borders and the limits of its person. It is in continuous and discontinuous interaction that this construction is made and that it endures. In other words, the subject is surrounded by a psychic envelope, in relation with body envelope concept, which is "figurative in the sense that it allows a cartography of the exchanges between the psychic world and the external world: others, culture and the natural world". ${ }^{18}$

The psychic envelope then constitutes an interface between the subject and the external world. The adaptation to the social environment, in other words normality, is dependent on the level of permeability of this interface. The more impermeable it is and the more the subject is closed in the external world, the more risk of maladjustment up to the level of autism. ${ }^{19}$ The more permeable it is and the more it is subjected to the flow of information coming from an external potentially threatening and dangerous world. This can lead to a need for transforming the reality of this world to defend themselves (e.g. from paranoia, schizophrenia) and paradoxically not divorced from reality. Between these two extremes of permeability of the interface it happens to have levels of adaptation and interactions that are different and more or less dependent on the external world.

In our modeling, we show a subject that is built in interaction with two systems which have as a function to educate him/her: the family and the school. This analogical design of the construction of the personality makes it possible to apprehend the psychic apparatus in construction, while being interested in the limits and the bonds which are woven with outside. The skin is the border that separates the body from outside, it fills a certain number of functions. Analogically, the body refers to the group; "to make bodies", is an expression which illustrates and establishes the link between the subject and the group..$^{20}$ The group thus has functions that can allow a differentiated becoming and consequently greater integration in its social environment. The family assume this role at first, in particular the mother for whom Anzieu $^{3,4}$ shows well how she takes an active part in the installation of the functions of maintenance/handling and containing/holding of the ego-skin.

\section{A proposal assessment of group envelope}

We thus suggest to apprehend the psychic envelope as an interface between the subject and its environment. It is represented by the functions filled by the groups in which the subject takes part, in particular with regard to the matter of reflection, the family and the school. The functions of the ego-skin allow the maintaining of psychic integrity, and adaption to the social environment. The family group also assumes these various functions in order firstly to preserve the subject as such and secondly to preserve the family group as a unity (family homeostasis). However the systemicians showed that the maintenance of homeostasis is done in the psychopathological families at the expense of the integrity of the subjects which compose them. ${ }^{21,22}$ This operation should be visible through the dysfunction of the functions of a "group ego-skin". We will call this psychic envelope "the psychic group envelope". $3-23$

\section{Toward an operationalization}

The tool: We suggest operationalization of the psychic envelopes using the FAST (Family System Test) test used to assess the family system in various configurations and to appreciate the representations or perceptions that various members of the family have. ${ }^{15-27}$ The instruction of this tool is very simple: "To explain to the family members how cohesion is portrayed, the evaluator at first places several figures close to one another and then places them further apart, while explaining that these patterns represent different degrees of cohesion among family members. The evaluator then elevates the figures with blocks of various sizes and explains that the differences in the vertical position correspond to levels of hierarchy within the family". ${ }^{26}$ The FAST is not a normative instrument like the majority of the tests. It aims to provide as much to the clinician and/or researcher as to the members of the family a metaphorical description of the family system. From this description, we will be able on the one hand to initiate at the subjects a psychical working-over of the movements of this system, and on the other hand to give of it an account at the time of an interview or follow-up. The choice of this projective tool returns account, according to us, of what we want to evaluate and argues itself in particular in the following way:

a. The FAST is based on the structural systemic theory. It makes it possible to interpret the operation of the group or to locate its dysfunction. What interests us here is the operation of the subject. More precisely the perception that he/she will have group 
functioning suggested at the time of the protocol, which will account for the organization of the internal groupality. We will articulate the observations of this organization to the functions of the psychic group envelope;

b. Cohesion and hierarchy refer to projection in the group of the Super-ego and the narcissistic shoring, as well as Ego ideal (relation and distance with reality; typical bond representation and ideal representation);

c. Flexibility such as it is questioned by the tool shows us the capacity of adaptation of the envelopes and consequently the capacity of adaptation of the functions of the envelope. Rigidification and bursting will be the two extreme forms which will show the dysfunction of it.

This tool thus offers a secure place of exchange and thinking to account for the limits of the psychic envelope ${ }^{18}$ Moreover, it opens the subject on a projection of the representations of objects and groupality, a setting in imaginary scene and an expression set of themes of psychic dynamics, near to a radiography with intra/interpsychic providing a direct interpretative reading towards the structural systemic theory applied in fact to the school system. ${ }^{16}$

Mode of reading : In using the adaptation of the FAST to the school world, each protocol is presented according to methods suggested by Gehring and Debry ${ }^{26}$ in their handbook. 6 situations are presented to the subjects, 3 for the family system and 3 for the school system. These situations are the typical situation, the ideal situation and the conflict situation. In each situation, the subject positions the figures (schematic male and female figures) on a square board. The protocols make it possible to retranscribe the positions of the figures, their identity, the hierarchy, the use of figures of colour if necessary, as well as the direction of their glance. Each figure is identified on the square board by initial, sometimes by initial with a number. Its initial makes it possible to identify of which member of the family it is (Figure 2).
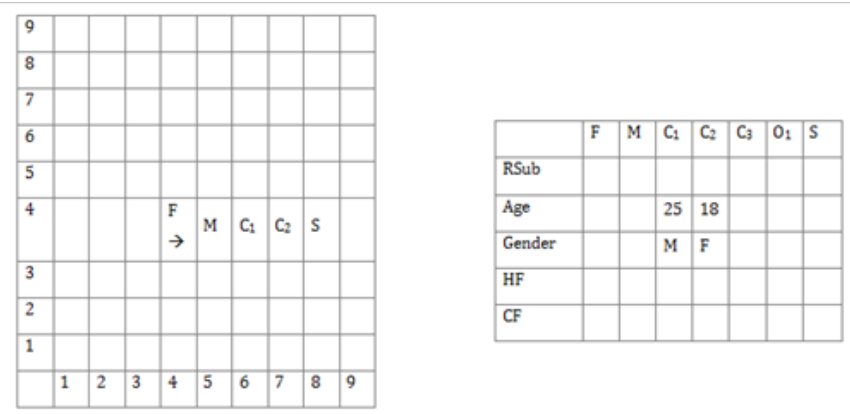

Figure 2 FAST, example of datas collection.

F: Father ; M: Mother ; $C_{1}, C_{2}$ : Brother and Sister; S: Subject.

For the family representations, the initial ones are: $\mathrm{F}$ for the father, $\mathrm{M}$ for the mother, $\mathrm{S}$ for the subject (or the initial one of its first name), and $\mathrm{C}$ followed by a number for the members of the siblings. When other members of the family are mentioned, the letter $\mathrm{O}$ is used followed by a number. The table located on the right of the figure specifies the relation to subject, on the line RSub, between each figure and the subject which makes the test: $\mathrm{Br}$ means brother, Si means sister. For the school representations, the initial ones are: $\mathrm{P}$ for pupils, A for adults and $\mathrm{S}$ for the subject (or the initial one of its first name). The status of each person is mentioned in the table on the right with the line RSub: Ma means manager, Pr means professor, and Bu means buddies. The arrows which are sometimes located on the square board indicate the direction of the glance of the figures. Sometimes, these arrows are insulated and represent then the glance of all the figures. The table located on right-hand side mentions, in addition to the age and the gender of the people represented, the level of hierarchy (HF) and the colour the case falling due (CF). The level of hierarchy is calculated by number and height of blocks used to elevate the figures.

\section{Between an oppositional school refusal and a rigidification of the psychic envelope: Basile}

Anamnestic datas: Basile is a $15 y$ years old adolescent who repeated a year in primary school, following difficulties of behaviour. After those, he was directed towards a special class which is called a "school of rehabilitation". Then he gets into the "SEGPA" (special section of general and professional education) of a secondary school. Classically, he says that the pupils who attend this section are the "insane ones", or many "like me, which cannot read". Repeating a year and school difficulties seem to be linked to the birth of his younger 8years old brother. He has spoken of being jealous of him at one time, although this is not the case anymore. He affirms to have had, one year before our meeting, an "adolescence crisis", during which he did not obey any more. But currently, he is calm and more obeying. He lives with his two parents and his little brother who is in second primary grade: "him, he likes the school". His brother has also repeated a year. His father, a road driver, was laid off for "economic reasons", and his mother occupies a job of maternal assistant in a school. The family have some financial difficulties. Basile's position is firmly against school, and is unambiguous. During the interview, he did not cease to express his hatred with regard to the adults of the school (teaching, manager, supervisors) and other pupils, mainly pupils of the "normal" cycle. We felt a pupil can revolt against people and a system which he/she does not understand (and refuses to understand). Basile admits readily that he is not liked at school, that he "is feeling bad there".

The FAST Family : Basile's typical situation shows a close family, hierarchical. He (S) says that it has been like that since he was born, changing just after with the birth of his little brother (C1). Moreover, the dyad of the two brothers ( $\mathrm{S}$ and $\mathrm{C} 1$ ) is distributed around the father (F) and of the parental couple, forming a not very cohesive subsystem (Figure 3). In spite of such a representation of the family system, he confided not getting on with his mother (M), and not often being at home. He is often outside, returns late in the evening (after 23:00 hours), and plays football with his buddies.
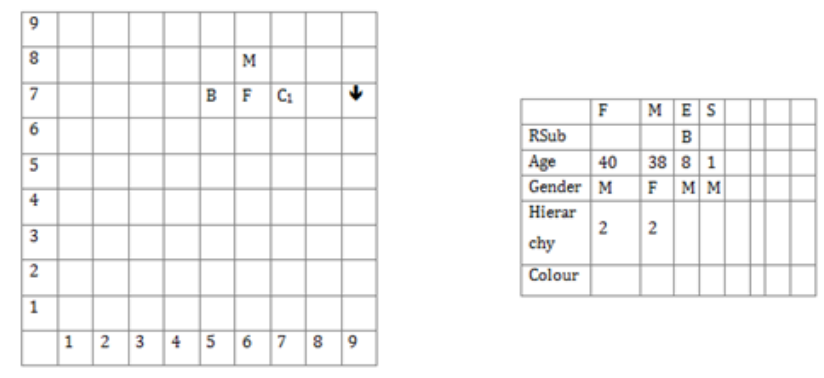

Figure 3 Basile, typical representation of family.

With regard to the ideal representation, he starts by declaring "I don't know", then "it is similar, I couldn't give a damn about it". By thus making distance rather than projection towards an ideal, he does not take the risk to destabilize this system with which he, however, seems in opposition. The conflict representation shows frequent arguments between the subject and his brother, often without founded reason. The representation does not evolve compared to the typical 
situation. The little brother moves away from the family system of two squares, reducing the cohesion of the family system, and a little more cohesion of the sibling subsystem. Moreover, when his brother is concerned in these conflicts, the subject represents the system by excluding the brother, "I calm it, if not my father calms it". On this price family cohesion is maintained. The subject seizes more power and rises on the same level as his parents. Another dissonance is locatable in this representation: the subject does not reveal any more of hierarchy whereas he seems to admit the parental authority, in any case not to be opposed to it, in the answers which he gives (Figure 4).
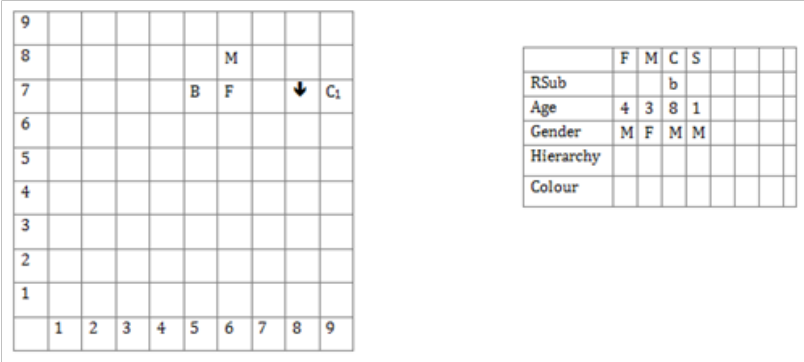

Figure 4 Basile, conflict representation of family.

B: Basile

School FAST : The typical situation reveals a not very cohesive system and no arranged hierarchy, disengaged (Figure 5). In addition to the traditional subsystems of adults, it is interesting to locate a subsystem of adults made up of a "couple of managers". In fact the director of the SEGPA (A4) and the Principal Adviser of Education (A5) do not appear a very cohesive couple, but closer compared to the other adults. The other subsystem of adults is composed of a couple of identified professors:

a. His professors of French (A2) and mathematics (A1).

b. A figure representing "the pawns" (A3, supervisors).

The three subsystems of this representation are located in three corners of the square board. In addition, the most cohesive subsystem is found in that to which the subject belongs, i.e. made up of its figure and a couple representing all his buddies of the college (P1 and P2). It is at the time of this situation that Basile delivers all the elements suitable to us to support an assumption of school refusal. In the same way, he uses for the first time the coloured figures, to represent the hatred which he feels facing the couple of managers ("stupid", "idiots", "I want to beat them") as his ambivalence with regard to the teachers ("they are weak", "one day they are friendly and the following day they are idiots") (Figure 5).
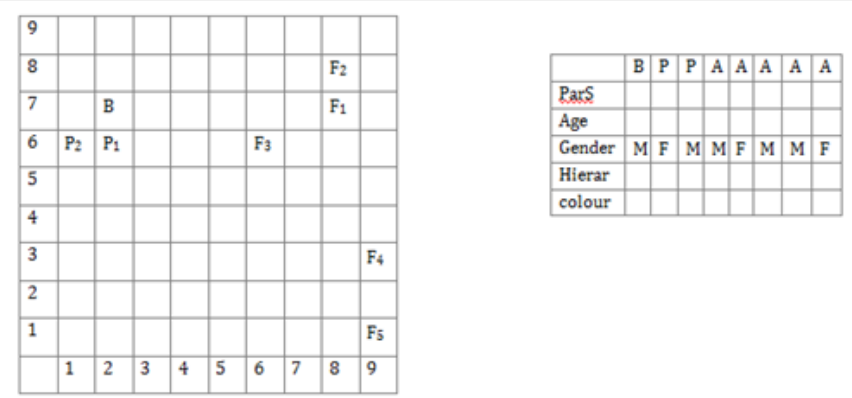

Figure $\mathbf{5}$ Typical representation of school.

$B$ : Basile; $A_{4}$ : SEGPA manager; $A_{5}$ : Principal education advisor; $A_{1}(M)$ : Mathematical teacher; $A_{2}(F)$ : French teacher ; $A_{3}$ : Supervisor ; $P_{1}(F)$ et $P_{2}(m)$ : All buddies of school
The ideal representation almost does not vary, even if he wishes that there be no more supervisors, and that the figure which represents them no longer appears (Figure 6). However, it is projected in an ideal. He starts, with the presence of his buddies, with a continuous general sympathy which passes by an "acceptable food" and "the absence of supervisors". Lastly, he leads to a new college and a desire that "they" all change. This continuation of ideas reveals the difficulty for Basile in being projected in feeling positively, lived like a danger, synonymous with the possibility of again being disappointed. Moreover, when we ask him what it is necessary to change, he refers from there to an answer steadier or socialized: "nothing, except teachers". After which we ask him whether he would like professors to be friendlier. There emerges an again fixed answer "that would not be used for nothing", he declares being "racist" with respect to the teachers and avoids answering them in comparison to other adults. As soon as a projection towards a better school is subjected to him, all occurs as if he felt taken with the trap and refused, at a given moment, to take the risk to be disappointed. Right now, the assumption of a dangerous idealization is set up, putting the question of the relationship between Ideal ego and the Ego ideal, of the primitive idealization, problems related to the primary identification (Figure 6).
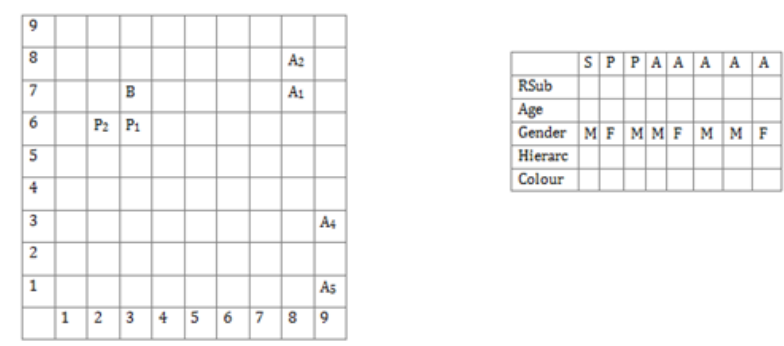

Figure 6 Basile, ideal representation of school.

The conflict representation reveals the only element of flexibility. Indeed, the figures change place, if it is not that it is a question of locating the subject in a corner of the square board, and to bring together the adults in the opposite corner (Figure 7). The couples of adults, teachers and managers, gather to face him. For the first time, he uses the glance to mean face to face between the figures (the other times, the glance of the figures was directed towards him but not towards the figure which represents him). Basile is only found, showing us the importance of the peers, of the buddies, like containing/holding and feeding his defensive system. With this occasion, he enables us to visualize the conflict of a subject facing the adults, with the other generations with which he does not communicate (he would like teacher's younger with which it could "speak").
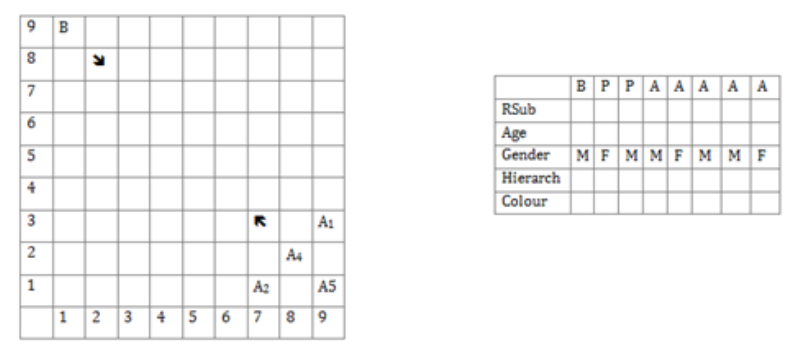

Figure 7 Basile, conflict representation of school.

A systemic and clinical reading: The condensation of the data of the FAST Family and the FAST School in a synoptic table (Table 1) leads us to carry out: 
a. Avertical reading revealing for each system the difficulty for Basile of modifying the representations. The family system keeps for the three situations the same configuration if it is not the distance of the little brother at the time of the conflict representation. The school system is modified in the ideal situation by the removal of a figure. The only notable modification relates to the conflict situation at the school, in which he is perceived only facing with the adults of the school.

b. A horizontal reading underlines the relations between what he lives in his family and in the school. The typical situation is very normative at the family level. At the school level, it shows us a system with many figures. This subject is isolated from the adults while being placed in a group of pupils. The adults form functional and distinct groups. These functions which are summarized with the law, the authority and the training are however not recognized to them (Table 1). In his family, he shows through the hierarchy and cohesion raised with his parents, while declaring his "absence" of home. He tends to want to preserve this representation while moving away, moving this conflict towards the school, towards the adults of the school of which he calls into question. The ideal representation, as well in the family ("they are similar, I don't give a damn about this") as in the school, shows a difficulty of idealization and the defensive mechanisms of avoidance concerned by anxiety generated by these situations. At the school, he moves the conflict once again, idealizing the absence of the supervisors, then teachers and finally the difference in generations with the teachers. The source of anxiety related to the difference in generation indicates a difficulty of managing the drive involvement, Basile "who cannot speak" with adults.

Table I Comparison of FAST Family and FAST School

\begin{tabular}{|c|c|c|}
\hline & Family & School \\
\hline Typical representation & $\begin{array}{l}\text { Dissonance between the representation and the } \\
\text { speech, not very present in his family, seems little } \\
\text { attached while showing a strong cohesion and the } \\
\text { recognition of the parental authority }\end{array}$ & $\begin{array}{l}\text { Little cohesion, reveals } 3 \text { couples, including } 2 \text { couples of adults. No } \\
\text { the hierarchy, and a strong cohesion of the subsystem of peers }\end{array}$ \\
\hline Ideal representation & $\begin{array}{l}\text { «I don't getting damn about this » Ideal } \\
\text { representation is similar to typical representation }\end{array}$ & $\begin{array}{l}\text { Even presentation and even mechanism compared to the idealization } \\
\text { that in the family. The presentation is almost not modified compared } \\
\text { to the typical situation, if it is not the absence of the supervisors }\end{array}$ \\
\hline Conflict representation & $\begin{array}{l}\text { The brother is excluded from the family system, } \\
\text { only blamed. The cohesion of the sibling subsystem } \\
\text { decreases }\end{array}$ & $\begin{array}{l}\text { The cohesion of the whole of the adults increases. The subject is } \\
\text { only found. }\end{array}$ \\
\hline
\end{tabular}

The conflict representation points on family side the source of the old conflict which is played, that is the birth of the little brother and his jealousy towards him. It also underlines the way in which Basile tends to preserve the configuration of the first family envelope by excluding the brother, by projecting the conflict and aggressiveness there ("he calmed down"). On the level of the school, he shows more flexibility and updates the displacement of the conflict: he is finding itself only facing with the adults, the latter not ensuring of function containing and avoid-excitation, being on the contrary its attackers. The negative identity comes in bond with the feeling from abandonment, it is essential like explanation of the abandonment which he felt with the birth of his brother, in a speech of the type "if my mother does not want ego, it is that I am bad".

\section{The psychic group envelope: rigidification and displacement of the conflict}

We suggest the assumption of a rigidification of the psychic group envelope insofar as the family conflict does not reduce cohesion whereas the conflict is internal and is not directed towards the outside. Basile tends to want to preserve the homeostasis of system. The psychic group envelope does not act as an interface, not allowing differentiation between the psychic components and the elements of the internal groupality. This rigidification can result in blocking the construction of the imagos, but also the "elimination" of the adults of the school who do not belong to the internal groupality, and thus do not come to take part in the construction of the imagos or other psychic components constitutive of the personality. The functional assumption of the psychic group envelope is supported moreover on the double following report:

I. Representations of the family system coercive: he indeed seems to perceive its family in a completely normative way. However, maintenance/handling shows us that it is not the case, that it gives us a hierarchical form of cohesion while stating not to be present in his family.

II. Diffuse generational boundaries at the school: they are respected and Basile presents neither cross-generational coalition, nor hierarchy reversal. However, it is seen well that he does not mobilize:

a. Coalition because he is not close to any adult at the school,

b. Hierarchy reversal taking into account the absence of perception of hierarchy at the school.

However, Basile seems to have difficulties on the cross-generational level, as if these borders constituted insuperable barriers. He tends to want to preserve the homeostasis of the family. The conflict with the younger brother represented the place of psychic conflict. Conflict related to the birth of his younger brother and the proximity which his brother keeps with his parents shows an unconscious desire to return to his only son position. The defensive mechanism faced with the aggressiveness that he feels for his brother is showed at the time of the ideal situation, a situation which he avoids (form of primitive idealization source of anxiety). He also avoids these conflicts by his systematic absence of the family environment, in which he returns only when it is a question of going to sleep.

The assumption of rigidification is articulated with the function of containing/holding of the ego-skin. Indeed, the function of containing/ holding that is obvious with Basile, in the placement of the figures, with his peers or his family, is also well at work as he also testifies presence of couples, both gender represented. But the function of containing/ holding seems to be lacking by "too", by a rigidity which prevents other functions from being supported. The dissonances that we located between the representations and his speech based this rigidity. Basile forges then a negative identity while avoiding the emotional 
investment source of an anticipated danger and a new disappointment. A clear economic net reinforcement is woven. The displacement of the conflict on the school is at the origin of this school refusal which he expresses openly. The rigidification of the function of containing/ holding signs its symptomatic nature. The articulation between the displacement of the conflict and the dysfunction of the function of containing/holding has as a consequence the non-integration of the adults of the school in the internal groupality. The pretence of adhesion foreseen as for the hierarchy at the school could result in this case from an adaptive conformism "reachable" in psychotherapy. Lastly, let us advance an assumption as to the function of maintenance/handling which ensures in particular the feeling of continuity of self and is supported by the process of primary identification. At Basile, the only continuity of self visible is due to the level of a negative identity. The few elements in connection with time, guarantor of continuity, are to be questioned: difficulty in locating "since when" situations, the speed of his answers, "the following day I forget". If it is hazardous to bring an interpretation there, these questions of identity and continuity of oneself can lead us (on the level of the function of maintenance) to consider how the process of identification of the parents, as well as the process of construction of the imagos, could be blocked at the time of the birth of his little brother.

${ }^{3}$ Food is using as a metaphor to illustrate how mother « feed » children with tenderness, love, affectivity ...

\section{Conclusion}

This test of modelling opens some theoretical and clinical reflections:

a. Firstly, the FAST proves to be a simple to use and promising tool for developments in term of articulation with the psychic envelopes and other concepts related to internal resonance of the group. If this work does not constitute a validation of the operationalization of the psychic envelopes, it opens an exploratory way of its reflection;

b. Then on the clinical area, the FAST showed, during this research and of a practical use in institution, an accessible and lucid tool for the subjects. It does not take the form of a testing sometimes badly lived and allows the opening towards very singular questionings on the question of the family bonds;

c. Finally, the FAST School widens this opening to the exploration of the bond and can lead the clinician and the subject to be wondered about displacements of conflicts, the capacities of adaptation.

In term of application, the FAST turns out very enriching on the clinical level in particular thanks to the projective material provided by this test insofar as it makes it possible to suggest various modes of reading, using various ideal models. The model of the psychic group envelopes constitutes a contribution to the interpretation of the FAST because it strictly speaking allows the articulation between a group level and a psychic level. Indeed, to analyze what occurs at the individual psychic level facilitates the articulation with what is analyzed on the group level. In other words, it allows an exhaustive systemic analysis from group system to the individual system. The group function of the psychic envelope is the assemblage point between group operation and individual operation. This reading notably appraises the complex link between ego-ideal and Ideal of Ego. It is the matter for adolescent to construct an Ideal of the Ego feeding his personality thanks to the good functioning of the psychic envelopes, with sometimes defensive returns in a position of Ego- Ideal, rigidifying envelopes, denying separation and the link which results from it, therefore returning any impossible destruction of this one, any attack counters this one. When the psychic group envelope is rigidified, one attends with a difficulty, even impossibility, of psychical working-over of the conflict. This difficulty of development is visible with the level of the functionality of the psychic group envelope: to take again the metaphor of Anzieu on the ego-skin, the psychic group envelope is what allows the exchange between inside and outside. This metaphor is articulated with the concept of transitional surface: the psychic group envelope is a transitional surface which ensures the subject the sufficient safety faced with drives of unconscious exerted on Ego (what would have as a consequence the projection of the drives towards outside, and towards the figures of attachment, and thus the confrontation to the subject of the fundamental interdicts of the murder of the father and of the incest). The use of the FAST and the application we propose allows joint assessment and brief psychotherapy and a prospective approach to the adolescent in his family and family in adolescence.

\section{Acknowledgments}

None.

\section{Conflicts of interest}

Author declares there are no conflicts of interest.

\section{Funding}

None.

\section{References}

1. Anzieu D. Le Moi-peau. Nouvelle Revue de Psychanalyse. 1974;195208

2. Anzieu D. The Group and the unconscious. Routledge, Abingdon, UK 1984. p.1-298.

3. Anzieu D. The Skin Ego. Yale University Press, London, UK. 1989. p.1-288.

4. Anzieu D. The Group Ego Skin. Group Analysis. 1999;32:319-325.

5. Anzieu D Martin JY. La dynamique des groupes restreints. Presses Universitaires de France, France. 1971. p.1-397.

6. Anzieu D. Introduction à l'étude des enveloppes psychiques. Revue de Médecine Psycho-Somatique. 1986. p.9-22.

7. Winnicott DW. Collected papers: Through paediatrics to PsychoAnalysis. Basic Books, New York, USA. 1958. p.1-28.

8. Chapelier JB. Avant-propos. In: Chapelier JB, et al. (Eds.), Le lien groupal à l'adolescence. Dunod, France. 2000. p.1-22.

9. Kaës R. Groupes internes et groupalité psychique: genèse et enjeux d'un concept. Revue de psychothérapie psychanalytique de groupe. 2005;2:9-30.

10. Kaës R. Linking, Alliances, and Shared Space. International Psychoanalytical Association, USA. 2007. p.1-269.

11. Kaës R. Le groupe dans le champ de la psychologie clinique. In E.Séchaud (Ed.), Psychologie clinique. Approche psychanalytique, Dunod, France. 1999.

12. Mol A. The body multiple: ontology in medical practice. Duke University Press, UK. 2002. p.1-216.

13. Tucker I. Towards the Multiple Body. Theory \& Psychology. 2006;16(3):433-440.

14. Tucker I. Psychology as space: Embodied relationality. Social and Personality Psychology Compass. 2011;5(5):231-238. 
15. Brandibas G, Jeunier B, Clanet C, et al. Truancy, School Refusal and Anxiety. School Psychology International. 2004;25(1):117-126.

16. Brandibas G. Le refus de l'école : six points de vue. L'Harmattan, France. 2007. p.1-268.

17. Srivastava P, Sehgal K, Singh TB. Determinants of school bullies: traits and behavior patterns, Journal of Psychology and Clinical Psychiatry. 2017;7(6):00461.

18. Doron J. Du moi-peau à l'enveloppe psychique. Genèse et développement d'un concept. In: Anzieu D, et al. (Eds.), Les enveloppes psychiques, Dunod, France. 2000. p.1-18.

19. Tustin F. Autism and childhood psychosis. Karnac Books, London, UK. $1972 ; 1-224$.

20. Kaës R. L'appareil psychique groupal. (2nd edn) Dunod, France. 2000.

21. Dessoy E, Goffin S, Wery A, et al. L'état stable du système famimial: une analyse organisationnelle. Thérapie Familiale. 1980;1:339-351.
22. Dessoy E. Vers une organisation du milieu humain. I. De l'intérêt du concept de "milieu" en psychothérapie institutionnelle et en approche systémique. Thérapie Familiale . 2007;14:311-300.

23. Anzieu D Houzel D, Missenard A, Enriquez M, et al. Les enveloppes psychiques. (2nd edn), Dunod, France. 2000.

24. Gehring TM, Wyler IL. Family-System-Test (FAST): A three dimensional approach to investigate family relationships. Child Psychiatry and Human Development. 1986;16(4):235-248.

25. Gehring TM, Wentzel KR, Feldman SS, et al. Conflict in families of adolescents: The impact on cohesion and power structures. Journal of Family Psychology. 1990;3:290-309.

26. Gehring TM, Marti D. Concept and psychometric properties of the FAST. In: Gehring TM, et al. (Eds.), The Family Systems Test (FAST)). Routledge, England, UK. 2001. p.3-27.

27. Gehring TM, Debry M, Smith PK. The Family System Test (FAST). (1st edn), Routledge, England, UK. 2001;1-320. 